www.wj-et.eu

\title{
Enhancement of educators' digital competences in the acquisition programming fundamentals in programming environment scratch
}

Arturs Medveckis * a, Liepaja University, Faculty of Education, Sociological Research Center, Email: arturs.medveckis@liepu.Iv, https://orcid.org/0000-0001-9290-2914

Tamara Pigozne ${ }^{\text {b }}$, University of Latvia, Scientific Institute of Pedagogy, https://orcid.org/0000-0002-4518-7644

Dzintars Tomsons c , Liepaja University, Faculty of Science and Engineering, https://orcid.org/0000-0003-3897$\underline{2027}$

\section{Suggested Citation:}

Medveckis, A., Pigozneb, T., \& Tomsons, D., (2021). Enhancement of educators' digital competences in the acquisition programming fundamentals in programming environment scratch. World Journal on Educational Technology: Current Issues. 13(4), 934-946. https://doi.org/10.18844/wjet.v13i4.6276

Received from July 31, 2021; revised from August 15, 2021; accepted from October 05, 2021

Selection and peer review under responsibility of Prof. Dr. Servet Bayram, Yeditepe University, Turkey. (C)2021 Birlesik Dunya Yenilik Arastirma ve Yayincilik Merkezi. All rights reserved.

\begin{abstract}
.
Life-long learning, including development of professional competence, is an essential paradigm of the $21^{\text {st }}$ century. The goal of this research is to analyse the quality and efficiency of the educators' professional competence enhancement programme dubbed "Fundamentals of Programming in Visual Programming Environment Scratch" in accordance with the following criteria: organization, lecturer's competence, quality of handouts, content, expectations, usefulness, applicability, and the overall assessment of the programme. The target group of the research is 98 educators of Latvia. Data was collected using close and open questions to ensure triangulation of data. Results were analysed using SPSS 20. The correlation coefficient was used to analyse the data. Per the results of the analysis, the acquisition of the professional competence enhancement programme, educators have significantly improved their knowledge in programming, as well as the digital competence in general.
\end{abstract}

Keywords: educators' professional competence; digital competence; fundamentals of programming; programming environment; Scratch.

\footnotetext{
* Address of correspondence: Arturs Medveckis, Liepaja University, Faculty of Education, Sociological Research Center, Email address: arturs.medveckis@liepu.lv
} 
Medveckis, A., Pigozneb, T., \& Tomsons, D., (2021). Enhancement of educators' digital competences in the acquisition programming fundamentals in programming environment scratch. World Journal on Educational Technology: Current Issues. 13(4), 934-946. https://doi.org/10.18844/wjet.v13i4.6276

\section{Introduction}

During the digital age, when the development of technologies is faster than humans' ability to adapt to the new conditions (Mackare \& Jansone, 2019), the computational thinking and coding related to it, programming, algorithmic thinking are emphasized as basic skills (Papadakis et al., 2017), that are equated in importance with numeracy and reading (Benton et.al., 2017). The choice of visual programming language is an important factor in programming acquisition (Iskrenovic-Momcilovic, 2017). Even though the range of digital resources and their application platforms in the $21^{\text {st }}$ century, as well as the resources, have become an integral part of the learning environment, their effectiveness is determined by their meaningful integration into the learning process (Becker et al., 2018; Daniela et al., 2019), therefore, the introduction of computational thinking and computer programming in compulsory education requires support measures for teacher training (Bocconi et al., 2016), offering to use opportunities to improve competencies in the use of visual programming environment Search (as a virtual space for educators for their innovative ideas and platforms for the development of computational thinking) (Papadakis \& Kalogiannakis, 2018).

During the pandemic caused by the rapid infection with the Covid 19 virus, the transition to distance learning, as well as remote out-of-office work, highlighted the level of competence of the technical support of the digital environment, the staff involved in the educational process and each person, which is related to professional activities or the application of pragmatically necessary opportunities to ensure the quality of daily life. The time of the pandemic in the education system revealed the broad coexistence of the technologies used and various digital platforms. In the process of distance education, pupils of comprehensive education schools and students of various educational institutions were faced with an unprecedented phenomenon of distance education - the need to react quickly and switch to different data media, applicable programmes, usable communication, and study programmes used by managers of different learning/study programmes, revealing certain problems in the educators' environment (Serafin, 2020).

The educators themselves were not so flexible and able to adapt to the new situation, because they felt comfortable using their usual communication platforms, self-acquired programmes, etc., but learners had to adapt to different forms of teaching staff's communication, so most educators are willing to invest time and effort in developing computational thinking skills and acknowledge that they need to have technological literacy and computational thinking skills to prepare for future challenges (Papadakis \& Kalogiannakis, 2018). In order to bridge the gap between the learners' digital literacy, educators need to acquire new digital competencies, which was realized by the implementers of Liepaja University (Latvia) teacher professional competence development programme "Fundamentals of Programming in Visual Programming Environment Scratch" in the amount of 12 hours, offering it to the target audience consisting of pre-school, primary school, and secondary school teachers. The programme participants were offered to learn the basics of the child-friendly programming platform Scratch - participate actively, create simple programmes and gain understanding of algorithms, cycles, conditions, variables and logical operators at the level required for primary school pupils, get practical advice on registration on this platform, adding students and formation of a common class in order to be able to implement successfully the basics of programming in their teaching work (Cárdenas-Cobo et al., 2020).

It is significant that the implemented programme for the improvement of teachers' professional competence was farsighted and focused on sustainability that still complies with the guidelines of the European Commission's Digital Education Action Plan (2021-2027), which is an updated European Union's (EU) policy initiative with an aim to support the sustainable and effective adaptation of EU Member States' education and training systems to the digital age, envisaging, as one of the points in the action plan, "offering opportunities, including qualitative and quantitative improvements in digital education, support for the digitization of pedagogical methods and the provision of the infrastructure 
needed for inclusive and sustainable distance learning" (Digital Education Action Plan (2021-2027, 2021). The same document identifies the need to foster the development of a high-performance digital education ecosystem in two priority areas and to strengthen the digital skills and competences needed for digitalization. To implement the first priority, it is important to provide a modern digital infrastructure, improve organizational capacity, involve competent and reliable digital training teachers in teaching, who develop and implement qualitative training content, acquire user-friendly and safe platforms that meet privacy and high ethical standards, strengthen digital skills and competencies (Goolsby et al., 2021).

As programming is often seen as a complex, tedious, and tiring task and a serious challenge, visual programming languages are offered to overcome it, e.g., Scratch (Cárdenas-Cobo et al., 2020) - a blockbased user-friendly programming environment (Evangelopoulou \& Xinogalos, 2017), which is widely accessible and which is constantly being developed, also creating opportunities for blind and partially sighted students to acquire computer programming skills (Goolsby et al., 2021). Moreover, it has a new application not only for learning programming, but also is widely used in interdisciplinary subjects, and its target audience is mainly beginners - pre-school, primary and secondary school pupils, students, and teachers (Tanrikulu \& Schaefer, 2011; Papadakis et al., 2014; Gorbans, 2014; Papadakis et al., 2017).

Based on the research findings, the programming knowledge and experience for the pupils, who have acquired Scratch, significantly facilitates learning: less time is needed to learn new topics, fewer learning difficulties, they have achieved higher levels of understanding, motivation, and self-efficacy (Armoni, Meerbaum-Salant, \& Ben-Ari, 2015), but for the students it has improved their academic performance in general (Cárdenas-Cobo et al., 2021). Discussions are taking place in the academic environments and professional circles about the best approach when teaching introductory programming (Papadakis et al., 2017).

The innovative approach is based on the philosophy of constructivism, new knowledge is acquired applying the resources created by the learners themselves (Weintrop et al., 2018); applying the graphical programming approach and freeing the user from syntax problems allows you to focus on programming logic (Tanrikulu \& Schaefer, 2011). Scratch is a popular choice of block-based programming languages (Logan, 2019) that consists of a dynamic, attractive, colourful, and simple graphical interface, offering work on projects relevant to everybody's interests such as animations, games, dialogues, simulations, various activities and interactive comics, and share them with the community (Beer \& Simmons, 2015). The dynamic features of the Scratch programming environment provide the creation of interactive and media-rich projects (Lazebna, Fedorova, \& Kuznetsova, 2019).

\subsection{Purpose of study}

The implementation of the second priority requires the development of digital skills and competences from an early age, improvement of digital literacy to combat misinformation, promotion of computing education, acquisition of artificial intelligence, acquisition of advanced digital skills in order to train IT professionals, while ensuring equal study and career opportunities for both young men and young women on the basis of gender equality. The goal of this research is to analyse the quality and efficiency of the educators' professional competence enhancement programme dubbed "Fundamentals of Programming in Visual Programming Environment Scratch" in accordance with the following criteria: organization, lecturer's competence, quality of handouts, content, expectations, usefulness, applicability, and the overall assessment of the programme

\section{Method}

\subsection{Participants}


The study was conducted from 23.08.2018 until 25.04.2019, and it was attended by 98 teachers of pre-school and comprehensive primary and comprehensive secondary education institutions, as well as teachers of interest education, 12-hour participants of the teacher professional competence enhancement programme "Fundamentals of Programming in Visual Programming Environment Scratch" from several regions of Latvia: 14 of them represented educational institutions of Kurzeme Region, 13 - Vidzeme, 36 - Latgale, but 35 - Riga.

As a result of the analysis of scientific literature, the criteria of quality and efficiency of professional competence improvement programmes have been identified - organization, lecturer's competence, quality of handouts, content, expectations, usefulness, applicability, and overall assessment (Pigozne \& Usca, 2015).

\subsection{Data collection tool}

Primary and secondary data have been obtained during the research process. The mixed methods approach was used to obtain primary data - based on the quality and efficiency criteria of the teacher professional competence enhancement programme identified as a result of theoretical analysis, closed and open questions were included in the questionnaire, thus ensuring triangulation. Respondents were asked to answer the closed questions with choices on the Likert scale, assigning them values in the range from 1 to 5 :

- organization, lecturer's work, quality of handouts and overall assessment of teachers' professional competence development programme, as well as self-assessment of knowledge and skills before and after their acquisition: "outstanding" (5), "very good" (4), "good" (3), "satisfactory" (2) and "poor" (1).

- acquisition of the content: "easy" (4), "relatively easy" (3), "relatively difficult" (2) and "difficult" (1).

- application of knowledge and skills: "yes" (5), "relatively -yes" (4), "relatively - no" (3), "no" (2) and "can't tell" (1).

- expectations: "comply" (3), "partly comply" (2) and "don't comply" (1).

- usefulness: "yes" (3), "partly" (2) and "no" (1).

Cronbach's alpha coefficient for the test plausibility check on the scale $(\alpha=.83)$

indicates good internal consistency.

\subsection{Analysis}

The Kolmogorov-Smirnov test has been used to determine the empirical distribution. As the empirical distribution did not comply with the normal $(p=.000)$, non-parametric data processing methods were used to obtain the secondary quantitative data - Spearman's Rank Correlation Coefficient to determine correlations between the quality of the programme and efficiency criteria, and Wilcoxon Two Related Samples Test to determine knowledge and skills dynamics between two dependent samples, as well as the descriptive analysis was performed, stating the standard deviation, arithmetic mean, median and mode, programmes for the quantitative data processing in the SPSS environment.

A content analysis has been performed for the open-ended questions, where the respondents were asked to substantiate their assessment. 
Medveckis, A., Pigozneb, T., \& Tomsons, D., (2021). Enhancement of educators' digital competences in the acquisition programming fundamentals in programming environment scratch. World Journal on Educational Technology: Current Issues. 13(4), 934-946. https://doi.org/10.18844/wjet.v13i4.6276

In order to reach the goal of the research- analyse the quality and efficiency of the educators' professional competence enhancement programme "Fundamentals of Programming in the Visual Programming Environment Scratch" - the following research questions were raised:

- What is the quality and efficiency of the 12-hour teacher professional competence development programme "Fundamentals of Programming in a Visual Programming Environment Scratch" offered by the Lifelong Learning Centre of Liepaja University (Latvia)?

- What criteria affect the assessment and usefulness of the teacher professional development programme?

- What are the development opportunities of the teacher professional development programme "Fundamentals of Programming in Visual Programming Environment Scratch" in the amount of 12 hours?

\section{Findings}

The quality of the organization of the implemented professional competence improvement programme for teachers is generally assessed very positively, taking into account that the excellent evaluation $(35.7 \%)$ and very good $(48.0 \%)$ represent the opinion of the majority of respondents. (Mean=4.23; $\mathrm{Me}=4.00, \mathrm{Mo}=5 ; \mathrm{SD}=.835$ ) (see Table 1). The neutral answer - "good" in 16.3\% of cases is also considered to be a positive assessment. $4.1 \%$ of respondents rated the course organization as satisfactory, which can be explained by the difficulties of overcoming subjective problems. No markedly negative assessment of the quality of the organization has been found. It complies with the results of other research on the participants' satisfaction with the organization of professional competence development programmes for teachers implemented by Liepaja University (UlmaneOzolina et al., 2019).

The lecturer's work in 51.0\% of cases has been assessed as excellent, which indicates the lecturers' professional competence - high level of knowledge, skills and attitudes, perfect application of methodological techniques and tools (Mean=4.41; $M e=5.00, M o=5 ; S D=.671$ ). The assessment expressed as "very good" by $38.8 \%$ also has a similar positive trend. Moreover, in $10.2 \%$ of cases, the assessment "good" indicates the positive attitude of the course participants. The rating "satisfactory" has not been expressed by any of the respondents, and the negative rating options have not been marked on the scale of the questionnaire.

The quality of handouts as a very good proportion with $53.1 \%$ dominates over other choices (Mean=4.20; $M e=4.00, M o=4 ; S D=.657$ ). The next positive opinion is "excellent" (33.7\%), followed by the opinion "good" (13.3\%). Other options ("satisfactory" and "poor") have not been negatively marked. In the assessment of the criteria presented in the table, in the ranking of $48.0 \%$ of the cases the assessment of the respondents' choices includes the evaluation "very good", followed by the evaluation "excellent" with 35.7\% and the evaluation "good" with 16.3\% (Mean=4.19; Me=4.00, Mo=4; $\mathrm{SD}=.698)$. No negative options have been identified.

The study confirmed the results of other studies - as the aim of the introductory courses is to make programming more interesting and accessible for beginners, their assessment is higher (Cárdenas-Cobo, et al., 2020), but the programme participants with some previous programming experiences are less satisfied than others (Tanrikulu \& Schaefer, 2011).

Table 1. Assessment and Overall Evaluation of Organization Quality, Lecturer's Work Quality, Handouts Quality of Educators' Professional Competence Enhancement Programme "Fundamentals of Programming in Visual Programming Environment Scratch"

\begin{tabular}{lcccc}
\hline $\begin{array}{l}\text { Descriptive } \\
\text { statistics indicators }\end{array}$ & $\begin{array}{c}\text { Quality of } \\
\text { organization }\end{array}$ & Lecturer's work & $\begin{array}{l}\text { Quality of } \\
\text { handouts }\end{array}$ & Overall evaluation \\
\hline Mean & 4.23 & 4.41 & 4.20 & 4.19 \\
\hline
\end{tabular}


Medveckis, A., Pigozneb, T., \& Tomsons, D., (2021). Enhancement of educators' digital competences in the acquisition programming fundamentals in programming environment scratch. World Journal on Educational Technology: Current Issues. 13(4), 934-946. https://doi.org/10.18844/wjet.v13i4.6276

\begin{tabular}{lcccc}
\hline Median & 4.00 & 5.00 & 4.00 & 4.00 \\
Mode & 5 & 5 & 4 & 4 \\
SD & .835 & .671 & .657 & .698 \\
$\%$ & & & - & - \\
Satisfactory & $4.1 \%$ & - & $13.3 \%$ & $16.3 \%$ \\
Good & $13.3 \%$ & $10.2 \%$ & $53.1 \%$ & $48.0 \%$ \\
Very good & $37.8 \%$ & $38.8 \%$ & $33.7 \%$ & $35.7 \%$ \\
Outstanding & $44.9 \%$ & $51.0 \%$ & & \\
\hline
\end{tabular}

In $57.1 \%$ of cases, the participants of the course considered the acquisition of the content of the offered professional competence improvement programme for teachers as relatively easy. In $22.4 \%$ of cases, the content of the course seemed rather difficult, but in $19.4 \%$ of cases it was considered as easy (Mean=2.95; $\mathrm{Me}=3.00, \mathrm{Mo}=3 ; \mathrm{SD}=.679$ ) (see Table 2 ). In $1 \%$ of cases, the acquisition of the teacher professional competence enhancement programme has been assessed as difficult. This distribution of results indicates the previous level of training of the teachers involved in the courses. It was quite easy for the teachers who work in the digital environment on a daily basis and teach computer science and programming themselves in educational institutions, while other course participants who are beginners in programming or have less work experience had a higher degree of difficulty in the teacher professional development programme.

Suggestions and proposals from participants with no or with less prior knowledge are aimed at the reduction of the pace of learning, respecting the successive step-by-step practice from the simplest to the most complex; there is a proposal to organize the implementation of the pedagogical professional competence enhancement programme in compliance with the level of prior knowledge and practical experience.

Participants of the teacher professional development programme, whose level of knowledge and skills is higher, would be interested in acquiring more in-depth knowledge, as well as acquisition of other programming platforms. Some recommendations are related to the organization of work organize the implementation of the teacher professional competence improvement programme for several days, so that there is not so intensive work during the day at the computer; controversial suggestions are about the need for handouts in a paper format - some consider the availability of digital material to be more age-appropriate and user-friendly.

Regardless of the course participants' training, there is a recommendation to emphasize the differentiation of the application of the acquired knowledge when teaching at school in different age groups.

Table 2.; Assessment of Content Acquisition of Teacher Professional Competence Enhancement Programme "Fundamentals of Programming in Visual Programming Environment Scratch"

\begin{tabular}{lc}
\hline Descriptive statistics indicators & Content \\
\hline Mean & 2.95 \\
Median & 3.00 \\
Mode & 3 \\
SD & .679 \\
$\%$ & \\
Difficult & $1.0 \%$ \\
Relatively difficult & $22.4 \%$ \\
Relatively easy & $57.1 \%$ \\
Easy & $19.4 \%$ \\
\hline
\end{tabular}


Medveckis, A., Pigozneb, T., \& Tomsons, D., (2021). Enhancement of educators' digital competences in the acquisition programming fundamentals in programming environment scratch. World Journal on Educational Technology: Current Issues. 13(4), 934-946. https://doi.org/10.18844/wjet.v13i4.6276

The results of the qualitative data content analysis confirm and refine the results of the qualitative data analysis. The respondents' opinions dominate in the open questions about the degree of difficulty of the content of the teacher professional competence enhancement programme (see Table 3):

- learning was easy, because in all cases the first emphasis was on the course leaders' competence, clarity of presentation, pace of work, methodological support and, in case of uncertainty, an individual approach. Secondly, the courses did not present any difficulties, as there was prior knowledge of programming, personal contact, and practical experience with Scratch, as well as the availability of teaching materials and examples in the Moodle environment.

- The cognition that learning was relatively easy is in most cases based on the course leaders' scrupulous theoretical presentation and practical demonstrations for solutions, despite their poor prior knowledge, but also those who had prior knowledge considered it as their advantage and rated the content as relatively easy. There was an opinion considering cooperation and feedback as important.

- It was relatively difficult for those respondents who lacked prior knowledge and who were not mathematics or programming teachers. The difficulty was for beginners in programming, who had the pace too fast, justified by a lack of knowledge of mathematics.

Table 3; Respondents' Opinions on Content Acquisition of Teachers' Professional Competence Enhancement Programme

The lecturer explained everything slowly and understandably, helped to eliminate mistakes; had worked a bit with the programme before; the lecturer explained and showed everything very well; had a little prior knowledge and the work with the lecturer was equal to the audience's abilities; a very good pace, well-considered work and prepared materials by the lecturer in the Moodle environment; the teacher explained to me everything in an understandable language, worked

जे practically; had done some work with Scratch before, there were both visual aids and a very good

蛋 narrative by the teacher; the teacher gave very clear explanations; the lecturer was able to explain programming, to demonstrate actions in a way that everyone could understand; the teacher was very competent and experienced, was interested in everyone to learn the subject, constantly followed the feedback; the lecturer tried to explain to everyone every detail; we worked at a moderate pace, stopping at difficulties; the teacher explained to us every detail, paid attention to potential mistakes.

The beginning was a bit too difficult; it would have been easy, if I had had a better prior knowledge in programming; if there is a teacher who explains mistakes, tells me what activities I have to do, then it seems quite easy; nevertheless, if it was just me, it would be more difficult; there were both easy and difficult tasks; had already acquired this and that in the environment; the lecturer's narrative was clear, understandable; if an issue emerges, the student gets some help; a very good work pace, very good materials, exciting tasks, the teacher oversees well the "pitch," a wonderful teacher who knows her field, good explanations, examples, easy to perceive.

Too scarce knowledge to work with Scratch; prolonged work on the screen tires eyesight and "switches off" thinking; no experience; no previous experience at all, even though I gained proper understanding during the course; no prior knowledge in programming; too complicated for beginners; too fast pace; had never worked with a programme like that before, it was hard to see from my seat what was written on the board, too fast pace; tasks could have been arranged from the easiest to the most difficult; no experience to work in the programme; started off with very complex tasks that are not applicable in the curriculum without prior knowledge; don't use such programmes on a daily basis; didn't have any prior knowledge; fast pace; it is difficult to go deep into the theme and understand it at once; I am not a maths specialist.

I am neither a programmer, nor mathematician, I want to learn gradually, not everything together in one course; too fast pace; the projects discussed in the lesson are intended for secondary school students; no knowledge in mathematics; lots of new terms, not sufficient previous experience. 
Medveckis, A., Pigozneb, T., \& Tomsons, D., (2021). Enhancement of educators' digital competences in the acquisition programming fundamentals in programming environment scratch. World Journal on Educational Technology: Current Issues. 13(4), 934-946. https://doi.org/10.18844/wjet.v13i4.6276

In $52.0 \%$ of cases, respondents have found opportunities to apply the knowledge by choosing an option that confirms it (Mean=4.27; $M e=5.00, M o=5 ; S D=1.011$ ) (see Table 4). $32.7 \%$ of the respondents were more likely to apply the knowledge in practice, choosing the answer "relatively yes". Doubts about the possibilities of applying the acquired knowledge were in $10.2 \%$ of cases, but $5.1 \%$ of the respondents were without a definite opinion. The answers "yes" and "relatively yes" indicate the innovative nature of the specific professional development programme for teachers, which provides new knowledge, while "relatively no", as it turned out in the discussions, the answers were chosen by those who already use and have adapted alternative programmes and work methods in the educational process, as well as those for whom in the professional career the pedagogical professional competence enhancement programme was as a means of self-growth promotion, but not as a transfer component of the acquired knowledge in their learners' environment.

The high level of expectations of $91.8 \%$ testifies to both the successful and motivated teachers' attitude towards the educational process and the high level of the teachers' professional competence development programme, intellectual and methodological support (Mean=2,95; $M e=3.00, M o=3$; $\mathrm{SD}=.275$ ) (see Table 5). Only $8.2 \%$ of respondents have admitted that their expectations only partially coincide with the offer and the course. Such an attitude has been expressed both by the most knowledgeable, theoretically, and practically working ambitious educators, as well as by those for whom the acquisition of the pedagogical professional competence enhancement programme has caused certain difficulties.

The results of Spearman's correlation analysis show that teachers 'expectations influence the assessment of the usefulness of teachers' professional competence enhancement programme $(r=.52$, $p<.001$ ) (see Table 6). Each participant of the teacher professional competence development programme has their own motivation to participate. Excluding the cases when only the confirmation of the course completion is important, the factor of expectations is more important, meaning the desire of each individual participant of the teacher professional competence development programme to learn something new that would supplement the previous knowledge, improve practical work skills, methodically prepare for further self-education process. Usefulness can be interpreted differently. It can be understood as knowledge acquisition, courses can be useful as a means of assessing selfassurance and personal preparedness potential, but usefulness prevails as an aspect of acquired knowledge, skills, methodologies, software applicability, respectively, knowledge transfer in the further education process provision in their learners' environment.

Table 4: Assessment of Application of Knowledge and Skills Acquired in Professional Competence Enhancement Programme "Fundamentals of Programming in Visual Programming Environment Scratch"

\begin{tabular}{lc}
\hline Descriptive statistics indicators & Application of acquired knowledge and skills \\
\hline Mean & 4.27 \\
Median & 5.00 \\
Mode & 5 \\
SD & 1.011 \\
$\%$ & \\
Can't tell & $5.1 \%$ \\
Relatively "no" & $10.2 \%$ \\
Relatively "yes" & $32.7 \%$ \\
Yes & $52.0 \%$ \\
\hline
\end{tabular}

The overall assessment of the teacher professional competence enhancement programme statistically significantly correlates with such quality criteria as course organization $(r=.75, p<.000)$, lecturer's competence $(r=.75, p<.000)$, quality of handouts $(r=.75, p<.000)$ and programme content $(r=.75$, $\mathrm{p}<.000$ ) (see Table 7). 
Medveckis, A., Pigozneb, T., \& Tomsons, D., (2021). Enhancement of educators' digital competences in the acquisition programming fundamentals in programming environment scratch. World Journal on Educational Technology: Current Issues. 13(4), 934-946. https://doi.org/10.18844/wjet.v13i4.6276

Table 5: Assessment of Acquired Expectations of Teachers' Professional Competence Enhancement Programme "Fundamentals of Programming in Visual Programming Environment Scratch"

\begin{tabular}{lc}
\hline Descriptive statistics indicators & Expectations \\
\hline Mean & 2.92 \\
Median & 3.00 \\
Mode & 3 \\
SD & .275 \\
$\%$ & \\
Partly comply & \\
Comply & $8.2 \%$ \\
\hline
\end{tabular}

The organization of the implementation of the teacher professional competence enhancement programme is largely related to the composition of the learners' groups, which is either voluntary and / or influenced by external factors, by which we mean the requirements set by employers to increase teachers' professional competence. Participants in the teacher professional development programme are often full-time employees in educational institutions, as well as the time limit for studies, attendance logistics and undivided attention to the acquisition of the teacher professional development programme is an important aspect of quality and satisfaction. The quality of the organization of the implementation of the teacher professional competence enhancement programme influences the participants' well-being, perceptual abilities, and satisfaction with the achieved results.

Optimal organization of the implementation of the educators' professional competence development programme, which includes the level of previous training of the participants, planning of course times, support of employers in order not to make it more difficult for employees to perform work functions, creates preconditions for its successful acquisition. The development of the content of the teacher professional competence improvement programme, which is created by the specialists of the respective field of science, has also been evaluated and accepted by experts in compliance with the project conditions. Its content is methodologically justified and includes a move from learning simpler elements to more complex ones. Theoretical viewpoints are linked to practical lessons which model the educational process that teachers will have to implement in the further educational process, multiplying the acquired knowledge and promoting its practical application in their students' audience. According to experts, the content of the programme may differ from the assessment of the participants of the teachers' professional competence enhancement programme.

Table 6: Correlation between Usefulness of Professional Competence Enhancement Programme "Fundamentals of Programming in Visual Programming Environment Scratch" and Participants' Expectations

\begin{tabular}{cc}
\hline Criteria & Expectations \\
\hline Usefulness & $\mathrm{r}=.52, \mathrm{p}<.001$ \\
\hline
\end{tabular}

Acquisition of the content of the teachers' professional competence development programme depends on both the learners' readiness and on the optimal solution of work organization, as well as on the lecturer's competence. The lecturer's competence depends not only on knowledge of the field and in-depth knowledge of specific issues, but also on pedagogical competence, which includes appropriate teaching methodology, lecturer's skills, and abilities to work with adult audience, respecting participants' individual abilities and taking into account psycho-emotional factors. 
Medveckis, A., Pigozneb, T., \& Tomsons, D., (2021). Enhancement of educators' digital competences in the acquisition programming fundamentals in programming environment scratch. World Journal on Educational Technology: Current Issues. 13(4), 934-946. https://doi.org/10.18844/wjet.v13i4.6276

Table 7: Factors Influencing Assessment of Teachers' Professional Competence Enhancement Programme "Fundamentals of Programming in Visual Programming Environment Scratch"

\begin{tabular}{ccccc}
\hline Criteria & $\begin{array}{c}\text { Organization of } \\
\text { courses }\end{array}$ & $\begin{array}{c}\text { Lecturer's } \\
\text { competence }\end{array}$ & $\begin{array}{c}\text { Content of } \\
\text { programme }\end{array}$ & $\begin{array}{c}\text { Quality of } \\
\text { handouts }\end{array}$ \\
\hline Assessment & $r=.79, p<.000$ & $r=.81, p<.000$ & $r=.72, p<.000$ & $r=.73, p<.000$ \\
\hline
\end{tabular}

Handouts provide methodological support, as well as testify to the professional competence of the authors of the teacher professional competence enhancement programme, who are usually also its implementers. Handouts are intended to provide support functions during the acquisition of teachers' professional competence enhancement programme, as well as to strengthen knowledge individually after the organized work group classes. Handouts may be in a printed form as well as in a digital format. It facilitates the acquisition of the content of the teachers' professional competence enhancement programme, strengthens knowledge, improves practical work skills and is useful for the acquisition level diagnostics and self-assessment.

The results of the Wilcoxon Two Related Samples Test show that the 12-hour acquisition of the Professional Competence Enhancement Programme "Fundamentals of Programming in the Visual Programming Environment Scratch" has significantly $(p=.000)$ improved knowledge and skills in programming in the Scratch programming environment and digital competence in general.

\section{Discussion}

The research results of the acquisition of the programming fundamentals of the teachers' digital competence development resources in the programming environment Scratch show compliance with the priorities defined by the European Commission towards "Europe Ready for the Digital Age". The assessment of the quality and effectiveness of the teacher professional competence enhancement programme is influenced by such factors as the quality of the organization, the lecturer's work and the quality and content of handouts, while the evaluation of its usefulness is influenced by teachers' expectations. The level of the organization of the implementation of the teachers' professional competence enhancement programme, discovered in the research, promotes its acquisition, which is facilitated by administrative support instruments, financial support, availability of digital resources and technical support capacity (Daniela, Visvizi, Gutiérrez-Braojos \& Lytras, 2019).

The acquisition of the content of the teacher professional competence development programme has been facilitated by the professionalism of adult educators, readiness for classes and methodological provision. The content of the teacher professional competence development programme has an innovative character, which opens opportunities for the course participants not only to reproduce the acquired knowledge, but also to develop creatively and improve digital skills, combining them with previously acquired knowledge and competencies (Papadakis, Kalogiannakis, Orfanakis \& Zaranis, 2017). Handouts are a resource for an interactive and personalized successful professional development programme for teachers, as well as for the enhancement of knowledge and skills and sustainability provision in the digital environment, thus making further progress in European digital education, contributing to the formation of a more digital and greener European Union.

Taking into account that the visual programming environment Scratch is user-friendly for different age groups, both individually and in collaboration with multiple players, it is developing essential digital skills required in the $21^{\text {st }}$ century (Bocconi, Chioccariello, Dettori, Ferrari \& Engelhardt, 2016). The acquisition of digital skills and programming skills contributes to the development of the education system by making a significant contribution in order to overcome the challenges identified during the Covid 19 pandemic, while ensuring a sustainable education process which has been raised in European policy-making documents such as the European Skills Agenda for Europe, The European Pillar of Social Rights Action Plan and Europe's Digital Decade: digital targets for 2030. 
The wide global number of users of the Scratch visual programming environment opens up opportunities for international collaboration between different users, which promotes networking and enhances the professional development of each participant, as well as promotes intercultural connections, increases tolerance, and obtains new knowledge in the fields of informatics and interdisciplinarity (Beer \& Simmons, 2015).

The quality of the implementation of the teacher professional development programme, which depends on the competence, content, and methodological provision of its leaders, meets high standards and participants' expectations, but their efficiency could be increased by improving work organization that does not overload participants' perceptual abilities and the groups would be organized, differentiating according to the level of preparedness (Armoni, Meerbaum-Salant \& BenAri, 2015) .

\section{Conclusion}

To ensure the sustainability of the teacher professional competence enhancement programme, the support system for independent further studies is successful, which is ensured by the availability of study and methodological materials in the open personalized Moodle system.

An important criterion for the quality and efficiency of the teacher professional competence enhancement programme is the high evaluation of its participants' learning process, which is achieved through intensive 12-hour work, saving time resources of participants and adult educators involved in the training process, using rationally the University's infrastructure and technical capacity.

The recommendations developed by the authors of the study for the improvement of the skills of using the visual programming environment Scratch and the digital competence of teachers envisage:

- Differentiation of the acquisition of the future professional competence development programme "Fundamentals of Programming in Visual Programming Environment Scratch" by organizing groups of teachers with and without prior knowledge.

- Improvement of methodological materials for adaptation of students of different age groups.

- After the acquisition of the Scratch basic programme of the visual programming environment, the involvement of teachers in lifelong learning, continuing the in-depth study of the professional competence development programme "Basics of Algorithm Development and Programming in the Visual Programming Environment Scratch."

- Development of networks of projects and other collaborative initiatives in their local community of education, as well as initiation of international partnership cooperation in the educational process using the visual programming environment Scratch.

- Monitoring and feedback acquisition on the further self-growth of the course participants and the application of the acquired knowledge and skills, which would form the base for further research, with the help of which to ensure the continuous improvement of the teachers' professional competence enhancement programme and high-quality further education of teachers.

\section{References}

Armoni, M., Meerbaum-Salant, O., \& Ben-Ari, M. (2015). From Scratch to "Real” Programming. ACM Transactions on Computing Education, 14(4), 1-15. https://dl.acm.org/doi/abs/10.1145/2677087

Benton, L., Hoyles, C., Kalas, I., \& Noss, R. (2017). Bridging Primary Programming and Mathematics: some findings of design research in England. Digital Experiences in Mathematics Education. https://link.springer.com/article/10.1007/s40751-017-0028-x 
Medveckis, A., Pigozneb, T., \& Tomsons, D., (2021). Enhancement of educators' digital competences in the acquisition programming fundamentals in programming environment scratch. World Journal on Educational Technology: Current Issues. 13(4), 934-946. https://doi.org/10.18844/wjet.v13i4.6276

Becker, S.A., Brown, M., Dahlstrom, E., Davis, A., DePaul, K., Diaz, V., \& Pomerantz, J. (2018). The NMC Horizon Report: 2018 Higher Education Edition. Austin, Texas, The New Media Consortium, 1-54. https://eric.ed.gov/?id=ED594367

Beer, P., \& Simmons, C. (2015). Hello App inventor!: Android programming for kids and the rest of us. Manning Publications, New York, USA. https://www.amazon.com/Hello-App-Inventor-Androidprogramming/dp/1617291439

Bocconi, S., Chioccariello, A., Dettori, G., Ferrari, A., \& Engelhardt, K. (2016). Developing Computational Thinking in Compulsory Education. Join Research Centre, European Commission. https://komenskypost.nl/wpcontent/uploads/2017/01/jrc104188 computhinkreport.pdf

Cárdenas-Cobo, J., Puris, A., Novoa-Hernández, P., Parra-Jiménez, Á., Moreno-León, J., \& Benavides, D. (2021). Using Scratch to Improve Learning Programming in College Students: A Positive Experience from a NonWEIRD Country. Electronics, 10, 1-15. https://www.mdpi.com/2079-9292/10/12/1470

Cárdenas-Cobo, J., Puris, A., Novoa-Hernández, P., Galindo, J., \& Benavides, D. (2020). Systems and Scratch: An Integrated Approach for Enhancing Computer Programming Learning. IEEE Transactions on Learning Technologies, 13, (2), 387-403. https://ieeexplore.ieee.org/abstract/document/8651403/

Daniela, L., Visvizi, A., Gutiérrez-Braojos, C., \& Lytras, M.D. (2019). Sustainable Higher Education and Technology-Enhanced Learning (TEL). Sustainability, 10(11), 3883. https://www.mdpi.com/356612

Digital Education Action Plan (2021-2027). (2021). Adaptation of education and training to the digital age. (2021). European Commission. Retrieved from: https://ec.europa.eu/education/education-in-the-eu/digitaleducation-action-plan IV

Evangelopoulou, O, \& Xinogalos, S. (2017). Myth Troubles: An Open-source Educational Game in Scratch for Greek Mythology. Simulation \& Gaming, 49(1),71-91. https://journals.sagepub.com/doi/abs/10.1177/1046878117748175

Goolsby, B., Kim, H. W., Pawluk, D., \& Fusco, G. (2021). A Tangible Block Editor for the Scratch Programming Language. ACM: Yokohama, Japan. https://dl.acm.org/doi/abs/10.1145/3411763.3451833

Gorbans, I. (2014). Programming Environment for Any Pupil - Scratch or Fundamentals of Programming in a Few Lessons. Retrieved from: https://edu.lu.lv/mod/book/view.php?id=29857\&chapterid=182

Iskrenovic-Momcilovic, O. (2017). Choice of visual programming language for learning programming. $\begin{array}{lllll}\text { International Journal } & \text { Co } & \text { Computers, } & 250-254 .\end{array}$ https://www.inderscienceonline.com/doi/abs/10.1504/IJTEL.2019.100478

Lazebna, N., Fedorova, Y., \& Kuznetsova, M. (2019). Scratch Language of Programming VS English Language: Comparing Mathematical and Linguistic Features. Physics and Engineering, 6, 34-42. http://journal.eujr.eu/engineering/article/view/982

Logan, L.B. (2019). Learn to Program with App Inventor. No Starch Press, San Francisco, USA.

Mackare, K., \& Jansone, A. (2019). The concept for e-material creating and formatting application prototype. Periodicals of Engineering and Natural Sciences, 7(1), 97-204. http://pen.ius.edu.ba/index.php/pen/article/view/363

Papadakis, S.J., \& Kalogiannakis, M. (2018). Evaluating a Course for Teaching Advanced Programming Concepts with Scratch to Preservice Kondegarten Teachers: A case Study in Greece. Retrieved from: https://www.intechopen.com/chapters/64583

Papadakis, S.J., Kalogiannakis, M., Orfanakis, V., \& Zaranis, N. (2014). Novice Programming Environments. Scratch \& App Inventor: a first comparison. In Proceedings of the Workshop on Interaction Design in Educational Environments, $1-7 . \quad$ Retrieved from: https://www.researchgate.net/publication/266613872 Novice Programming Environments Scratch_A $\mathrm{pp}$ Inventor a first comparison

Papadakis, S.J., Kalogiannakis, M., Orfanakis, V., \& Zaranis, N. (2017). The Appropriateness of Scratch and App Inventor as Educational Environments for Teaching Introductory Programming in Primary and Secondary Education. International Journal of Web-Based Learning and Teaching Technologies, 12 (4), 58-77. 
Medveckis, A., Pigozneb, T., \& Tomsons, D., (2021). Enhancement of educators' digital competences in the acquisition programming fundamentals in programming environment scratch. World Journal on Educational Technology: Current Issues. 13(4), 934-946. https://doi.org/10.18844/wjet.v13i4.6276

https://www.igi-global.com/chapter/the-appropriateness-of-scratch-and-app-inventor-as-educationalenvironments-for-teaching-introductory-programming-in-primary-and-secondary-education/219609

Pigozne, T., \& Usca, S. (2015). Case of Latvia in the Evaluation of Adult Education: Issuesand Solutions. In V. Lubkina, S. Usca (Eds.) Proceedings of the International Scientific Conference, May 22nd-23rd, 2015, Volume IV, 165-177. Rezekne: Rezeknes Augstskola. Retrieved from: http://journals.ru.Iv/index.php/SIE/article/view/357/552

Serafin, C. (2020). Innovation of the Teaching of Modern Interactive and Multimedia Tools in Teaching. In O. Titrek, Sezen-Gultekin, G. (Eds.) . 6th International Conference on Lifelong Education and Leadership Proceeding Book, July 16-18, 2020, 179-187. Sakarya University, TURKEY. https://www.springer.com/gp/book/9789813345935

Tanrikulu, E. \& Schaefer, B.C (2011). The Users who Touched the Ceiling of Scratch. Procedia - Social and $\begin{array}{lll}\text { Behavioral Sciences, } & 28, & 764 \\ \text { https://www.sciencedirect.com/science/article/pii/S187704281102579 }\end{array}$

Ulmane-Ozolina, L., Jansone, A., Magazeina, I., \& Barute, D. (2019). Technology enhanced learning in teachers' professional development. Periodicals of Engineering and Natural Sciences, 7(1), 216-221. http://pen.ius.edu.ba/index.php/pen/article/download/400/256

Weintrop, D, Hansen, A.K., Harlow, D.B., \& Franklin, D. (2018). Starting from Scratch: Outcomes of early computer science learning experiences and implications for what comes next. In Proceedings of the 2018 ACM Conference on International Computing Education Research, 142-150, ACM. https://dl.acm.org/doi/abs/10.1145/3230977.3230988 